\title{
Compreender para melhor formar: conexões entre o curso de pedagogia e a educação de jovens e adultos
}

Jéssica Asencio Figueiredo

Graduanda em Pedagogia. Faculdade de Filosofia, Ciências e Letras de Ibitinga FAIBI. jessicasencio86@gmail.com

Erica Rodrigues do Nascimento Augustini

Doutoranda do Programa de Pós Graduação em Educação Escolar - FCLAR UNESP - campus Araraquara. Docente da Faculdade de Ciências e Letras de Ibitinga - FAIBI. ericaaugustni@yahoo.com.br

\section{Célia Regina Rossi}

Doutora do Programa de Pós Graduação em Educação Sexual e Educação Escolar, da FCLAR - UNESP - Araraquara/SP. celiar@rc.unesp.br 


\section{Resumo}

Este estudo busca apresentar uma atividade prática da disciplina de Fundamentos da Educação de Jovens e Adultos, inserida no curso de Pedagogia, em uma Faculdade Municipal do interior de São Paulo. Tal atividade é um recorte do Projeto de Alfabetização e Letramento para Idosos - PROALLI - desenvolvido numa instituição de idosos, tendo como foco estabelecer conexão entre a teoria e a prática na formação docente junto a este público que, por motivos diversos, foi excluído do processo de alfabetização em idade estabelecida pela legislação vigente. Para fins metodológicos, a experiência caracterizou-se pela abordagem qualitativa, configurando-se num estudo de caso que seguiu para análise descritiva. Mediante a distribuição de eixos temáticos inseridos em disciplinas como Português e Matemática, formou-se seis grupos para a sondagem inicial com os/as alunos/os inscritos no Projeto. O resultado consistiu na reflexão dos formandos para uma formação que corresponda às especificidades deste público.

Palavras-chave: Alfabetização. Educação de Jovens e Adultos. Letramento. Idosos.

\section{Abstract}

This study seeks to present a practical activity in the Fundamentals of Education of Youth and Adults, inserted in the course of Pedagogy, in a College Hall of the interior of São Paulo. This activity is an extract of the Literacy Project Literacy and for the elderly - PROALLI - developed in an institution for the elderly, focusing on establishing connection between theory and practice in teacher training next to this audience who, for various reasons, was excluded from the process of literacy in age established by current legislation. For methodological studies, the experience was characterized by the qualitative approach, setting up a case study that followed for descriptive analysis. Through the distribution of thematic axes inserted into disciplines like English and mathematics, formed six groups for the initial survey with the students/members in the project. The result was the reflection of the trainees for a formation that corresponds to the specific characteristics of this audience.

Keywords: Literacy. Youth and Adult Education. Information. The elderly. 


\section{Introdução}

As pesquisas sobre este tema retratam que embora vivamos em uma sociedade letrada e, não obstante os esforços movidos pelos órgãos educacionais no sentido de superar o fenômeno do analfabetismo, os índices de pessoas incapazes de decifrar linguagens e códigos ainda são alarmantes, sendo essas pessoas relegadas à margem da sociedade, muitas vezes, sendo excluídas de uma dinâmica social onde os estímulos visuais se fazem tão presentes.

Os índices de analfabetismo são ainda mais gritantes entre a população idosa, haja vista que os mesmos provêm de uma época onde o acesso ao ensino básico, muitas vezes, era dificultoso, isso quando não se viam obrigados a deixar a escola para trabalhar desde os primeiros anos da juventude, auxiliando no sustento da casa.

Partido desta consciência mais ampla e, considerando que a Lei de Diretrizes e Bases da Educação Nacional (LDB no 9.394/96) estabelece em seu "Art. 37. A educação de jovens e adultos será destinada àqueles que não tiveram acesso ou continuidade de estudos no ensino fundamental e médio na idade própria”, foi elaborado o Projeto de Alfabetização e Letramento para Idosos (PROALLI), o qual começou a ganhar seus primeiros contornos durante as aulas de Fundamentos da Educação de Jovens e Adultos I, na turma do segundo ano de Pedagogia da Faculdade de Filosofia, Ciências e Letras de Ibitinga.

Para tanto, o enfoque dessa proposta é procurar favorecer o desenvolvimento de processos construtivos necessários ao aprendizado da leitura e da escrita por idosos, procurando dar aos mesmos a compreensão acerca da importância da língua em seu contexto sociocultural, de forma identificar a função social da escrita e da leitura, valendo-se do potencial linguístico prévio do educando durante o processo de aprendizagem.

Assim, essa experiência adveio da necessidade em investir qualitativamente no curso de formação docente, por meio da disciplina Fundamentos da Educação de Jovens e Adultos, na tentativa de aliar teoria e prática educativa.

Foram traçados como objetivos do PROALLI aliar teoria e prática pedagógica voltada para a Educação de Jovens e Adultos, preocupando-se com as especificidades que correspondem a esta modalidade de ensino. 
Para ser posto em prática, foi escolhido como reduto o Lar São Vicente de Paula, asilo situado na cidade de Ibitinga-SP, que alberga população idosa de toda a região, onde, após autorização dos responsáveis e apuração do número de idosos interessados nas aulas, passou-se a dar início ao projeto.

O presente trabalho não tem a pretensão de ser posto como um modelo a ser seguido, consistindo em uma vivencia com a qual podemos contribuir socialmente para a alfabetização de idosos, onde, após o emprego de metodologias inseridas numa abordagem humanista e sócio-interacionista de ensino, foi possível se chegar aos objetivos esperados.

\section{Metodologia}

A metodologia de pesquisa adotada no presente trabalho foi a qualitativa analítico-descritiva.

Segundo Godoy (1995), a pesquisa qualitativa se relaciona à procura de respostas a questões relacionadas ao estudo das sociedades, ou seja, a investigação qualitativa é uma forma de estudo da sociedade, centrada na forma como as pessoas interpretam e dão sentido às suas experiências e ao mundo que as cerca.

Existem diversos tipos de abordagem que utilizadas no âmbito da pesquisa qualitativa, mas todos eles visam compreender a realidade social (HOLLOWAY, 1999).

Para Malhotra (2006, p. 156), a pesquisa qualitativa "é uma metodologia de pesquisa não estruturada e exploratória baseada em pequenas amostras que proporciona percepções e compreensão do contexto do problema”.

Godoy (1995) aponta que a pesquisa qualitativa parte de questões de interesse amplo, os quais vão se definindo ao longo do desenvolvimento do estudo, mas que, geralmente, implicam na obtenção de dados descritivos sobre pessoas, lugares e processos interativos, através do contato direto do pesquisador com a situação estudada.

O elemento escolhido para tipificar a presente pesquisa qualitativa foi $o$ analítico-descritivo, na qual, segundo Triviños (2006), os dados coletados são ricos em descrições de pessoas, situações, fatos, históricos, comportamentos, atitudes etc., baseando-se a pesquisa na fenomenologia, sendo que, por isso, os resultados se basearão na percepção de um fenômeno inserido em determinado contexto. E, é analítico o 
método ao passo em que a análise dos dados segue um processo indutivo, partindo o pesquisador de evidências capazes de comprovar ou negar as suposições iniciais.

\section{Resultados e Discussão}

O conceito de alfabetização não pode se restringir apenas ao processo de aquisição e desenvolvimento da linguagem sob seus aspectos fonêmicos e grafêmicos, ultrapassando o âmbito puramente formal e adentrando às abordagens sóciointeracionistas da língua.

Landsman (1993, apud POSSAS, 1999) entende que três concepções complementam-se quando falamos sobre alfabetização. Para a autora, ser alfabetizado equivale a ser capaz de desempenhar um conjunto de atividades associadas ao uso prático; ser alfabetizado, para a autora, é ser detentor de poder político, econômico e mental; e, por fim, ser alfabetizado, para autora, é ser detentor das formas de expressões contidas em livros, tornando-se consciente de apreciar o valor estético das mesmas.

O conceito de alfabetização deve ser bastante amplo para que inclua a abordagem mecânica do ler e escrever, para que promova o enfoque da língua escrita como meio de expressão ou compreensão, dando autonomia e especificidade ao aprendizado em relação à linguagem oral e escrita, promovendo uma conscientização social do indivíduo (Soares, apud Kramer, 1986).

Consoante as premissas Freirianas, alfabetizar é, sobretudo, conscientizar o indivíduo do nível social em que o mesmo está inserido e, como se sabe, o método Freiriano consiste em três etapas peculiares: a investigação, a tematização e a problematização.

A investigação consiste na fase em que o alfabetizador delimitará o grupo social que será alfabetizado para que, em seguida, insira-se nesse grupo para realizar a observação do mesmo, apreendendo, assim, as peculiaridades e particularidades em evidência (SOARES, 1999).

De posse dessas informações, o alfabetizador deve promover a tematização, contextualizando os temas escolhidos na fase anterior, possibilitando ao alfabetizando a percepção crítica de sua realidade. Por meio dessa fase, surgem novos temas a serem abordados, os quais, por fim, levarão à fase da problematização, fase em que será desenvolvida nos alunos a conscientização em relação ao papel social por eles ocupado e 
a superação de eventuais obstáculos através do uso dos códigos linguísticos (Soares, 1999).

Compreendemos que o processo de alfabetização deve ser visto como uma ferramenta de libertação, capaz de levar os alfabetizandos à compreensão crítica da realidade que os circunda.

Partindo dessas premissas metodológicas o projeto passou a ser estruturado pensando, inicialmente, no público alvo, no caso ficou decidido que seria feita uma tentativa de parceria com o Lar São Vicente de Paula.

Ainda nesse primeiro momento já se pensou em elaborar um questionário visando explicar o projeto à pessoa responsável pelo Lar São Vicente de Paula e verificar o interesse da instituição em integrar o projeto de alfabetização e letramento.

Com o interesse demonstrado pela instituição, a turma do segundo ano de Pedagogia juntamente com a professora começou a pensar e elaborar uma ficha cadastral, a fim de obter um levantamento do número de idosos que gostariam de participar das aulas do PROALLI. Por meio das fichas cadastrais apurou-se que oito idosos estariam interessados nas aulas.

De posse dessas informações, o projeto foi estruturado a partir das disciplinas Língua Portuguesa e Matemática, organizadas e divididas por eixos temáticos, formado com as/os alunas/os do curso de Pedagogia, mediante distribuição e decisão coletiva dos temas para cada grupo ${ }^{1}$, sendo eles:

- Grupo 1: Oralidade e Leitura;

- Grupo 2: Escrita, Análise e Reflexão do Sistema de Escrita;

- Grupo 3: Sistema de Numeração;

- Grupo 4: Operações;

- Grupo 5: Grandezas e Medidas;

- Grupo 6: Espaço e Forma;

Esses grupos foram pensados com a finalidade de se analisar os conhecimentos prévios dos idosos frente às temáticas tratadas, consistindo em atividades de sondagem para que, posteriormente, as estratégias de ensino se adequassem à realidade investigada,

\footnotetext{
${ }^{1}$ Ao descrever a experiência, os discentes de Pedagogia serão identificados como monitores.
} 
respeitando os princípios estabelecidos pelas leis, diretrizes e outros referenciais que reforçam a necessidade de considerar os deferentes ritmos de aprendizagem, bem como a história de vida desse público.

Não obstante os eixos apresentados, durante o projeto preocupou-se em trabalhar a questão da socialização dos idosos entre si e com os pesquisadores, pois, entendemos que a socialização é ferramenta de grande importância no processo de ensino aprendizagem, pois, conforme Paulo Freire ensina (2002, p. 68), "Ninguém educa ninguém, ninguém educa a si mesmo, os homens se educam entre si, mediatizados pelo mundo".

Cada um dos grupos acima citados, com datas e horários pré-definidos junto à administração do Lar São Vicente de Paula, compareceram no local para desenvolver as atividades de sondagem pensadas e planejadas previamente.

Consoante um planejamento idealizado a carga horária semanal de 4 horas, sendo 2 horas para cada grupo, o projeto ocorreu num período de três semanas totalizando uma carga horária de 12 horas.

Os grupos eram compostos por quatro ou cinco integrantes que realizaram sua organização didático-metodológica pensando em coletar os conhecimentos prévios dos/as alunos/as.

O primeiro grupo a desenvolver as atividades com os idosos foi o grupo 1, trabalhando a oralidade e a leitura. Este primeiro contou com a presença de 5 idosos e o que foi possível perceber é que, na questão de oralidade, a maioria, se se comunicava bem sendo que alguns apresentaram fala, aparentemente de ordem fonológica ou mesmo por um fator cultural, Necessitando de intervenções pedagógicas à partir dessa primeira análise como forma de melhorar a comunicação entre eles e de um modo geral.

Durante a realização da atividade houve muita interação entre os idosos e os monitores presentes no momento. Por meio de conversas realizadas levantou-se que alguns desses idosos nunca foram a uma escola, outros sabiam escrever o próprio nome, mas não que reconhecessem todas as letras e processos de escrita, apenas por que alguém ensinou a escrita do nome, e outros dois possuíam um conhecimento maior em relação à temática, pois eram alfabetizados.

Neste ponto, importante ressaltar os ensinamentos de Paulo Freire (1989), para quem saber ler e escrever mecanicamente o próprio nome, no âmbito da educação de 
jovens e adultos, não é estar alfabetizado, pois a alfabetização de jovens e adultos tem incorporada em si a tomada de decisões:

Inicialmente me parece interessante reafirmar que sempre vi a alfabetização de adultos como um ato político e um ato de conhecimento, por isso mesmo, como um ato criador. Para mim seria impossível engajar-me num trabalho de memorização mecânica dos babe-bi-bo-bu, dos la-le-li-lo-lu. Daí que também não pudesse reduzir a alfabetização ao ensino puro da palavra, das sílabas ou das letras (FREIRE, 1989, p. 13).

Quando o conteúdo de leitura foi iniciado, foi possível perceber que, pelo menos, dois idosos ficaram mais apreensivos. A parte de leitura teve início utilizando cartaz com a música "Pirulito que bate-bate" que foi afixada à parede e realizada a leitura apontando com a régua cada sílaba lida. Neste momento, os idosos apresentaram bastante dificuldade e, por esse motivo, a leitura foi feita mais duas vezes a fim de obter maior familiarização com a cantiga, sendo que posteriormente, cada aluno/a teve acesso à letra da música para que acompanhassem a cantiga com o dedo, procedimento este conhecido como leitura de ajuste, esse procedimento consiste no ajuste dos segmentos do texto falado - que o educando conhece de memória - aos segmentos escritos, ou seja, pela localização dos itens lexicais a partir daquilo que educando sabe que está escrito (WEISZ, 2014)

sendo essa uma informação muito relevante para o planejamento das estratégias de ensino.

Logo na sequencia foi solicitado que identificassem as palavras ditadas, escolhidas antecipada e estrategicamente pelo grupo de monitores primeiramente com lápis e em um segundo momento com canetinha colorida buscando incentivar e motivar no interesse pelo trabalho desenvolvido.

Os dois idosos que são alfabetizados realizaram toda a atividade e um terceiro idoso também finalizou a atividade, porém este copiou do "vizinho", enquanto que os outros dois não foram capazes de identificar nenhuma palavra.

Reconhecemos a falha nesta ocasião, uma vez que a orientação era para realizar o ditado individualmente. Porém, por ser a primeira experiência, foi importante vivenciar um procedimento didático mal executado e suas consequências, neste ponto, relevante mencionar os ensinamentos de Freire (2001, p. 39), segundo o qual “[...] o 
FIGUEIREDO, J. A. et al. Compreender para melhor formar: conexões entre o curso de pedagogia e a educação de jovens e adultos. R. Cientifica UBM - Barra Mansa (RJ), ano XXII, v. 19, n. 37, 2. Sem. 2017. p. 78-96.

ISSN 1516-4071

importante é que a reflexão seja um instrumento dinamizador entre teoria e prática”, assim não basta que os profissionais reflitam, é essencial que essa reflexão resulte na tomada de decisões transformadoras, levando os educadores a pensar acerca dos desejos, vontades e historias dos educandos.

Percebendo essa imensa dificuldade apresentada pelos idosos, optaram por desenhar letras e procurar saber se conseguiam reconhecer ao menos as letras que compõe o próprio nome, mesmo assim não conseguiram encontrar e compreender quais eram as letras.

Procurando adentrar mais na ideia de leitura, questionaram se os idosos já sabiam ler, apenas os dois alfabetizados informaram que "sim", porém ao ser solicitada a leitura o senhor alegou que não enxerga muito bem e, portanto, não quis realizar a leitura solicitada. Para finalizar o primeiro encontro trabalharam uma cantiga.

Nessa mesma semana, o grupo 2 esteve no asilo para trabalhar o eixo de Escrita, Análise e Reflexão do Sistema de Escrita. No dia que estiveram presentes no Lar São Vicente de Paula vieram para a aula 9 idosos, ou seja, quatro a mais que o encontro anterior, porém apenas um que esteve no primeiro encontro voltou para participar da continuação do projeto.

Desse novo grupo formado, três deles sabiam escrever e os demais não possuíam nenhum conhecimento de escrita.

Ainda assim, o grupo procurou realizar a sondagem planejada. A sondagem foi feita apenas com os três idosos que disseram saber escrever e o grupo trabalhou a sondagem individualmente, ditando uma palavra e em seguida o idoso a escrevia.

Outro obstáculo apresentado pelo grupo 2 são as questões de dificuldades motoras, auditivas, visuais e psicológicas que os idosos possuem. De acordo com o grupo esses problemas dificultaram o processo de sondagem e se sentiram perdidos nesse momento, portanto optaram por realizar adaptações no que haviam pensado como atividades.

Percebendo a importância da socialização para os idosos, pois através de relatos o grupo soube que homens e mulheres ficam em alas separadas e, portanto, o contato entre os mesmos é restrito, o grupo 2 decidiu trabalhar mais as conversas e desenvolvimento social dos idosos, permitindo que contassem suas histórias de vida, piadas para descontração dos mesmos, tramitando o projeto, assim, para o aprendizado e socialização. 
$\mathrm{Na}$ semana seguinte foi o grupo 3 que compareceu ao Lar São Vicente de Paula, dando início ao trabalho no eixo temático da Matemática. O grupo 3 trabalhou com o Sistema de Numeração, em um primeiro momento acreditou-se que os idosos estavam indispostos. Neste dia o grupo contou com a presença de 5 idosos.

Durante o planejamento de aula a ser desenvolvido com os idosos o grupo optou por iniciar apresentando algumas placas com números e solicitando que os idosos falassem qual era aquele número mostrado, mas levaram números baixos e, com isso, sentiram que estava muito fácil e eles estariam achando a atividade muito simples.

Os idosos costumam jogar bingo e por esse motivo qualquer número apresentado era muito fácil de reconhecer. O grupo percebeu que se esqueceu de considerar os conhecimentos prévios dos idosos, portanto, ao notar essa facilidade apresentada começaram a ditar números maiores conforme orientação dada em aula, e ainda assim os idosos conseguiam identificar, com exceção de alguns, sendo possível obter um diagnóstico mais fiel e próximo de seus conhecimentos reais.

Em seguida, realizaram um bingo, "cantando" os números sorteados para que os idosos identificassem na cartela, por jogarem diariamente apresentaram muito facilidade com a brincadeira e o reconhecimento dos números.

No mesmo dia o grupo 4 realizou atividades no campo das operações com a presença de 4 idosos. Durante conversa inicial percebeu-se que há limitação física, motora, visual, auditiva, entre outros fatores já mencionados pelos grupos anteriores, além disso, notaram que os idosos participam das atividades muito mais pela necessidade de interação com outras pessoas do que pelo aprendizado em si, o que, dentro de uma abordagem sócio-interacionista, consiste numa formação integral do indivíduo.

A abordagem sócio-interacionista busca caracterizar os aspectos tipicamente humanos do comportamento, de forma a elaborar hipóteses de como as características humanas se formam ao longo da história do indivíduo (VYGOTSKY, 1996).

Este grupo optou por utilizar notas "falsas" de dinheiro para realizar as operações de soma e adição, através de questionamento conseguiram descobrir que alguns idosos reconheciam as notas pelo número, mas a maioria reconhecia pelo desenho.

$\mathrm{Na}$ terceira semana o grupo 5 chegou ao asilo e conversou com a pessoa responsável pela instituição, esta informou que as meninas poderiam entrar nas alas e ver 
FIGUEIREDO, J. A. et al. Compreender para melhor formar: conexões entre o curso de pedagogia e a educação de jovens e adultos. R. Cientifica UBM - Barra Mansa (RJ), ano XXII, v. 19, n. 37, 2. Sem. 2017. p. 78-96.

ISSN 1516-4071

quais idosos tinham interesse em participar da atividade. O eixo trabalhado foi o de grandezas e medidas.

O grupo 5 precisava fazer uma sondagem com os idosos para reconhecer quais os conhecimentos dos mesmos em relação a grandezas e medidas, para isso optaram por levar fita métrica à aula. Inicialmente propuseram medir a altura dos idosos, mas com a presença de muitos cadeirantes acabaram medindo a altura somente dos demais, o que não incomodou aos idosos que souberam levar na brincadeira dizendo que achavam que ainda lembravam-se da sua altura.

Em seguida apresentaram a fita métrica questionando qual a sua função e o que poderiam comprar por metro. Neste momento os idosos realizou uma atividade na qual deveriam circular quais os objetos que se encaixavam nessa categoria.

Durante a atividade se descobriu que um dos idosos trabalhava com montagem de móveis, outro com venda de tecidos, o que se tornou um facilitador na realização da atividade como um todo. A princípio, o grupo acreditou que poderia se deparar com idosos que desconhecessem os sistemas de medidas e, por isso, a existência dos dois idosos no grupo foi um elemento surpresa. No entanto, ainda com o elemento surpresa, o trabalho realizado foi muito positivo e o grupo foi capaz de obter um feedback muito bom por parte dos idosos, concluindo que, se tivessem de rever as atividades aplicadas aos idosos, teriam as alterado, optando por incorporar atividades mais voltadas para o ensino lúdico, já que é mais atraente e interessante para os idosos inseridos nesse contexto. De acordo com as ideias iniciais para o projeto, ainda não era o momento de atividade, mas de sondagem. Essa preocupação comprometeu um pouco a sondagem.

Por fim, no mesmo sábado o grupo 6 realizou sondagem sobre espaço e forma, tiveram oito idosos presentes. O grupo apresentou as formas geométricas básicas a eles e descobriram que alguns deles já conheciam e outros ainda não.

Um fator apontado pelo grupo é a questão das limitações apresentadas pelos idosos, a dificuldade motora foi o mais ressaltado, porém as atividades foram realizadas com sucesso. E a interação com os idosos, conversas superam as expectativas e torna a experiência maravilhosa.

Para realizar a sondagem os monitores desse grupo optaram por apresentar uma atividade de reconhecimento das formas geométricas básicas, onde em uma folha havia o desenho de um quadrado, um triângulo, um círculo e um retângulo na parte superior da folha e mais abaixo aparecia a imagem de várias dessas mesmas formas geométricas 
embaralhadas. Para iniciar a sondagem procuraram, por meio de diálogo, mostrar aos idosos essas formas geométricas com uso de material manipulável em tamanho grande para que todos pudessem através dessa manipulação ter um contato maior e, assim, o reconhecimento das figuras geométricas requeridas.

Após esse primeiro momento de manipulação do material, as monitoras solicitaram que os idosos pintassem as quatro figuras alinhadas no topo da folha de atividades para que, posteriormente, com o conhecimento adquirido através do diálogo e contato com o material disponibilizado os idosos realizassem a segunda parte da atividade que era reconhecer as mesmas formas geométricas que estavam embaralhadas em maior quantidade no restante da folha de atividades, pintando cada uma com a mesma cor utilizada no início da sondagem.

Porém, o grupo acredita que a atividade planejada não gerou muito interesse dos idosos, acreditam ainda que deveriam ter optado por trabalhar mais no contexto lúdico com a finalidade de apreender a atenção dos idosos que pretendem participar do projeto.

Todos os grupos que foram ao asilo desenvolver as atividades de sondagem com os idosos salientaram sobre a importância da socialização na realidade dos idosos do Lar São Vicente de Paula, a ideia de conversar e trocar informações, logicamente combinando com o aprendizado visado pelo PROALLI.

A partir do que foi apresentado ao longo de todo o projeto e realizando uma análise grupo a grupo, pensando no eixo trabalhado e a metodologia adotada consideramos que o grupo 1, responsável pelo eixo Oralidade e Leitura optou por iniciar com a leitura de uma música, no caso "Pirulito que bate-bate" considerando que os idosos já pudessem conhecê-la, o que representaria um facilitador desse momento de leitura.

Dessa forma, conforme salienta Tadeu Breda (2009), "O segredo para ensinar a ler é dar condições para o aluno resolver problemas que lhe permitem avançar como leitor e escritor, confrontando-se com textos desde o início da alfabetização”. Foi exatamente isso que o Grupo 1 buscou praticar.

Ao iniciar o trabalho, o grupo não esperava que os idosos já soubessem as letras, mas sim que acionassem outros conhecimentos, como a disposição gráfica dos versos, a observação das letras iniciais e finais, mesmo sem conhecimento prévio. Para tanto, optou-se pela leitura da música, por três vezes, procurando a ideia de "texto 
memorizado" a fim de que na fase seguinte da aula a questão da memorização colaborasse com as atividades, porém muitos dos idosos possuem conhecimento nulo em relação às letras, sendo que sequer reconhecem as letras do próprio nome.

O grupo seguinte, responsável por trabalhar o eixo Escrita, Análise e Reflexão do Sistema de Escrita deveria realizar uma sondagem visando descobrir as hipóteses de escrita de cada idoso presente. Bem como salienta Mara Mansani (2016), "Sondagem é a atividade de diagnóstico das hipóteses de escrita de cada aluno de uma turma de alfabetização e é usada para avaliar a evolução do processo de aprendizagem”, ou seja, essa sondagem de escrita deverá ser realizada periodicamente ao longo do processo de alfabetização idealizada pelo PROALLI com a finalidade de compreender e analisar os avanços apresentados pelos idosos.

A atividade pensada para essa primeira sondagem foi exatamente a que prega Mara Mansani (2016) "produção espontânea de uma lista de palavras, sem apoio de qualquer fonte e nem intervenção do professor", portanto, foram ditadas palavras de determinado campo semântico considerando que essas palavras são comuns ao cotidiano dos idosos.

As palavras utilizadas foram: Abacaxi, manteiga, suco e pão. Para finalizar a atividade de sondagem os idosos deveriam escrever a seguinte frase: Ontem comi pão com manteiga. Terminando a frase era solicitada a leitura da frase que acabaram de escrever.

Um ponto levantado pelo grupo foi o fato de não saberem como lidar em relação aos idosos que não sabiam escrever. E, aqui como sugestão, apontamos o trabalho com o próprio nome do idoso, solicitar que escrevessem o nome na folha oferecendo ajuda, caso necessário, e a partir do nome deles levantar questionamentos sobre as letras que o compõem, tentar realizar a leitura simultânea ao apontamento das letras e sílabas com o dedo. Dessa forma, seria possível frisar algumas das letras do alfabeto e reforçar a leitura pausada do próprio nome, que nesse momento emergiria como um facilitador desse processo de aprendizado.

Ademais, o único ponto que enfatizamos aqui é a questão de não haver um levantamento mínimo de hipótese de escrita dos idosos que estavam presentes na aula e alegaram não saber escrever, pois durante as aulas de Fundamentos da Educação de Jovens e Adultos I pudemos perceber que muitos adultos que não tiveram a oportunidade de escolarização na idade certa têm vergonha de tentar realizar algumas 
atividades, com isso queremos levantar a seguinte questão: será que esses idosos realmente não sabem escrever nada? Será que sabem ao menos escrever o próprio nome e tem conhecimento dessas letras que o compõem? Ou ainda, ficaram com vergonha devido a alguma limitação motora? Essas são algumas questões que ficaram sem resposta.

Por sua vez, o grupo 3 adentrou no eixo matemático e foi responsável por questões sobre o Sistema de Numeração. Conforme descrito anteriormente esse grupo optou por iniciar a aula levantando placas com alguns números e solicitando que os idosos dissessem qual era esse número e em seguida trabalhou o sistema numérico através de uma atividade lúdica que é o bingo.

A questão aqui é que o grupo ao mesmo tempo em que supôs e levou em consideração os conhecimentos prévios dos idosos ao optar por trabalhar um bingo, esqueceu-se desse mesmo conhecimento prévio ao iniciar a aula mostrando números que, obviamente, por eles jogarem bingo constantemente, já saberiam qualquer um desses números solicitados.

Com isso, queremos salientar que o caminho adotado pelo grupo 3 era coerente, porém faltou atentar ao fato de que todo ser humano, qualquer que seja sua fase de vida carrega consigo uma bagagem intelectual vasta e, no caso dos idosos essa bagagem pode ser ainda maior.

$\mathrm{Na}$ sequência o grupo 4 buscou abordar as operações matemáticas, mais especificamente as operações irmãs, no caso, adição e subtração.

A ideia adotada para abordar o conteúdo, foi eficaz, pois os idosos, conforme pudemos notar nas socializações feitas pelos grupos, sempre se preocupam com o recebimento da aposentadoria e em pagar suas contas, por esse motivo, o trabalho com notas falsas de dinheiro apresentou-se eficaz.

Através dos envelopes com notas de dinheiro falso, os idosos puderam desenvolver os conceitos de adição e subtração, além disso, através dos questionamentos em sala de aula conseguiram percebem quais idosos realmente reconhecem a nota pelo número representado nela ou pelo desenho da mesma. Como esperado alguns dos idosos reconhecem apenas pelo desenho, mas outros tanto reconhecem o número em questão.

Um fato que poderia ser relevante nesse processo educacional, que ajudaria na apreensão dos conceitos abordados é o que afirma Célia Maria Carolino Pires, coordenadora da Pós-Graduação em Educação Matemática da Pontifica Católica de 
São Paulo (PUC - SP) “a importância de o professor questionar, debater e socializar com a classe as soluções encontradas pelos alunos” acreditamos que essa socialização e apresentação de motivos pelos quais chegou e acredita naquele resultado pode ser uma fonte de aprendizado, pois através de seus conhecimentos um idoso pode colaborar com o aprendizado do outro.

Visualizamos que o eixo matemático beneficiou-se pelo fato dos idosos jogarem bingo e utilizarem dinheiro para compras e recebimento de aposentadoria, pois a partir desse conhecimento prévio dos mesmos é possível englobar diversos conceitos matemáticos que pretendemos que os idosos adquirissem no processo de aprendizagem.

Em seguida foi a vez do grupo 5 realizar uma sondagem sobre Grandezas e Medidas. Compreendemos que a utilização da fita métrica levada ao asilo por esse grupo foi igualmente genial, pois trabalhar grandezas e medidas utilizando-a torna o conteúdo mais significativo já que faz uso de material concreto e palpável aos idosos.

Partindo dos conhecimentos prévios dos idosos acerca do uso da fita métrica e sua utilização, foi possível realizar algumas medições como a altura de alguns dos idosos que estavam participando da atividade no dia, além de levantar novos questionamentos durante a realização da atividade seguinte, como por exemplo, "O que podemos comprar por metro?”.

Um ponto de extrema importância e que foi muito bem abordado pelas integrantes do grupo é o que salientam Carlos Roberto Vianna e Emerson Rolkouski (2014, p. 17) sobre a necessidade de trabalhar questões em que os idosos se "ponham mobilizados em práticas efetivas de medições”, pois de nada adianta o professor construir materiais que os educandos somente vejam, não possam tocar, compreender seu uso, não façam medições que se sintam contextualizados.

Encerrando as atividades do PROALLI em seu primeiro semestre de aplicação, o grupo 6 compareceu ao Lar São Vicente de Paula abordando conceitos sobre Espaço e Forma. De acordo com o planejamento pensado pelas integrantes desse grupo trabalharam com os idosos as formas geométricas básicas: quadrado, triângulo e círculo.

Conforme discutido em sala de aula alguns dos idosos presentes já conheciam essas formas geométricas enquanto outros não possuíam esse conhecimento, o trabalho, aqui, foi mais voltado às atividades de desenho e pintura das formas.

Percebeu-se, neste grupo, a necessidade de trabalhar o conteúdo de forma mais lúdica, contextualizada e palpável aos idosos com a finalidade de aproximá-los de tais 
conceitos, uso e importância de tal conhecimento, que é muito bem ressaltado por Nascimento (et al. 2014, 11) ao afirmar que devemos "mostrar aos alunos a importância do estudo da Geometria para as nossas vidas e também para o exercício de muitas profissões, seja na cidade ou no campo”. Esse fato não era difícil de comparar, pois sabemos que um dos alunos trabalhava com montagem de móveis e isso traz embutido nos conhecimentos conceitos de formas e espaços geométricos.

Por fim, é possível inferir que todos os grupos perceberam a necessidade de socialização dos idosos, pois os mesmos apreciam conversar e compartilhar suas vivências e, com isso, a atenção gerada durante a realização do PROALLI no Lar São Vicente de Paula foi de extrema importância para os idosos, sendo capaz de gerar conhecimentos básicos e novas vivências sociais aos mesmos.

É crucial que o docente possua sensibilidade para observar cada ação, cada manifestação do seu aluno para que possa analisar seus avanços no processo de aprendizagem.

O processo inicial de sondagem realizado pelo PROALLI se mostrou bastante válido, representando fonte de crescimento pessoal e profissional a todos os envolvidos na realização do projeto o qual, espera-se, seja levado adiante, conduzindo-o a um aperfeiçoamento, de forma a atingir a aprendizagem significativa dos idosos que dele participem.

\section{Considerações}

Diversas são as considerações que podem ser apresentadas acerca do trabalho desenvolvido com os idosos do Lar São Vicente de Paula por meio do PROALLI sendo, contudo, complicado especificar todos os aspectos que os alfabetizandos desenvolveram ao longo do projeto.

O desenvolvimento deste projeto nos oferece conclusões tanto relacionadas às práticas de alfabetização de idosos, quanto à situação de analfabetismo que as camadas mais baixas da sociedade se encontram, bem como, a situação em que se encontram aqueles que não tiveram direito à educação no período previsto em lei.

O PROALLI propôs a aplicação de um método de alfabetização de idosos que foge ao estabelecido tradicionalmente nesta área e, quando posto em prática, resultou bastante eficaz, pois proporcionou aos idosos não apenas o conteúdo a registros escritos 
e matemáticos, como proporcionou um aprendizado interativo, promovendo a socialização, elemento este de grande importância para os residentes do Lar São Vicente de Paula, proporcionando aos alfabetizandos um desenvolvimento propício às capacidades de leitura e escrita.

Com relação ao aprendizado da escrita, foi possível superar diversos dos obstáculos iniciais, especialmente o de os alunos não se acharem em condições de aprender a ler e a escrever devido à idade e particularidades da mesma (como aspectos visuais, mentais e motores).

Inicialmente, houve muita relutância na superação desses obstáculos, especialmente porque muitos dos participantes pareciam acreditar que a atividade não "levaria a nada", demonstrando, assim, a importância de um tratamento mais lúdico do aprendizado e letramento dos idosos.

Com relação ao ensino dos conteúdos matemáticos, houve maior participação por parte dos idosos e, foi possível notar que os mesmos apresentaram menores dificuldades em lidar com os números, especialmente porque, frequentemente, participam de bingos promovidos pela instituição.

Quando postos em contato com notas falsas de dinheiro, foi possível constatar que, alguns dos idosos as identificavam pelas cores e símbolos, sendo que poucos deles as identificavam pelos números e, a afinidade com esses números se mostra essencial, pois os idosos apresentam preocupações como receber a aposentadoria e pagar as contas.

Podemos considerar, ainda, que a socialização promovida pelo PROALLI também se apresentou bastante relevante, pois, os idosos residentes do Lar São Vicente de Paula sentem necessidade de comunicar-se com outras pessoas, haja vista viverem em relativa reclusão em relação ao mundo exterior, essa socialização promovida pela ação do PROALLI afigurou-se essencial para despertar a curiosidade dos idosos e, consequentemente, para promover o aprendizado dos mesmos, ganhando corpo, assim, a ideia de que a socialização aliada ao ensino lúdico dos idosos é capaz de promover um aprendizado significativo.

Por tudo que foi exposto, concluímos, assim, que nenhum trabalho de educação social conseguirá resultados satisfatórios se não se adequar à realidade dos educandos, essa adequação e a consideração do conhecimento prévio dos alfabetizandos é capaz de proporcionar a construção adequada do aprendizado, seja para os alunos quanto para os docentes. 


\section{Referências}

BRASIL. Lei no 9.394, de 20 de dezembro de 1996. Lei de Diretrizes e Bases da Educação Nacional. Disponível em: <www.planalto.gov.br/ccivil/LEIS/L9394.htm>. Acesso em: 27 de Maio de 2017.

BREDA, T. Leitura feita pelo aluno, antes de saber ler convencionalmente. Revista Nova Escola. Rio de Janeiro: Março, 2009. Disponível em:

$<$ https://novaescola.org.br/conteudo/2486/leitura-feita-pelo-aluno-antes-de-saber-lerconvencionalmente>. Acesso em: 27 de Maio de 2017.

FREIRE, P. A importância do ato de ler: em três artigos que se completam / Paulo Freire. - São Paulo: Autores Associados: Cortez, 1989. . Pedagogia da autonomia: saberes necessários à prática educativa. 20 ed.

São Paulo: Paz e Terra, 2001. Pedagogia do oprimido. 32.ed. Rio de Janeiro: Paz e Terra, 2002.

GODOY, A. S. Introdução à pesquisa qualitativa e suas possibilidades. Revista de Administração de Empresas, São Paulo, v.35, n.2, p.57-63, mar./abr. 1995.

HOLLOWAY, I. Basic Concepts for Qualitative Research. Basic Concepts for Qualitative Blackwell Science. Oxford, UK., 1999.

KRAMER, S. Alfabetização: dilemas da prática. Rio de Janeiro: Dois Pontos, 1986.

MALHOTRA, N. Pesquisa de marketing: uma orientação aplicada. 4.ed. Porto Alegre: Bookman, 2006.

MANSANI, M. 5 principios para a hora de pensar numa sondagem na alfabetização. Revista Nova Escola. Rio de Janeiro: 08 de Agosto de 2016. Disponível em: $<$ https://novaescola.org.br/conteudo/16/5-principios-para-a-hora-de-pensar-numasondagem-na-alfabetizacao >. Acesso em: 27 de Maio de 2017. 
NASCIMENTO, A. A. S. B; TORTORA, E; [et. al.]. A geometria e o ciclo de alfabetização. In: BRASIL. Pacto Nacional pela Alfabetização na Idade Certa-Caderno 5 Geometria. Brasília, MEC/SEB, 2014f. 96 p. Disponível em: $<$ http://pacto.mec.gov.br/images/pdf/cadernosmat/PNAIC_MAT_Caderno\%205_pg0 01-096.pdf>. Acesso em: 27 de Maio de 2017.

POSSAS, W. M. Compreensão e dominio da escrita: vale o escrito. In: MEC. Educação de Jovens e adultos. Brasília: SEED, 1999.

SOARES, M. Letramento: um tema em três gêneros. São Paulo: Autêntica, 1999125 p.

TRIVIÑOS, A. N.S. Introdução à pesquisa em ciências sociais: a pesquisa qualitativa em educação. São Paulo: Atlas, 2006.

VIANNA, C. R.; ROLKOUSKI, E. Grandezas e Medidas a partir do universo infantil. In: BRASIL. Pacto Nacional pela Alfabetização na Idade Certa - Caderno 6 Grandezas e Medidas. Brasília, MEC/SEB, 2014g. 80 p. Disponível em: < http://pacto.mec.gov.br/images/pdf/cadernosmat/PNAIC_MAT_Caderno\%206_pg00 1-080.pdf>. Acesso em: 27 de Maio de 2017.

VYGOTSKY, L. S. A formação social da mente. Rio de Janeiro: Martins Fontes, 1996.

WEISZ, T. A aprendizagem do sistema de escrita: questões teóricas e didáticas in: MORTATTI, Maria do Rosário Longo; FRADE, Isabel Cristina Alves da Silva (orgs.) Alfabetização e seus sentidos: o que sabemos, fazemos e queremos. Marília: Oficina Universitária; São Paulo: Editora Unesp, 2014. 